\title{
Estratégias de Manejo de Inverno e Verão Visando ao Controle DE Conyza bonariensis E Bidens pilosa ${ }^{1}$
}

\author{
Winter and Summer Management Strategies for Conyza bonariensis and Bidens pilosa Control
}

\author{
OLIVEIRA NETO, A.M. ${ }^{2}$, CONSTANTIN, J. ${ }^{3}$, OLIVEIRA JR., R.S. ${ }^{3}$, GUERRA, N. ${ }^{3}$, DAN, H.A. ${ }^{3}$, \\ ALONSO, D.G. ${ }^{4}$, BLAINSKI, E. ${ }^{3}$ e SANTOS, G. ${ }^{3}$
}

\begin{abstract}
RESUMO - Conyza bonariensis é uma das principais plantas daninhas da região Sul do Paîs; com a seleção de biótipos tolerantes e resistentes ao herbicida glyphosate, demandas são crescentes por alternativas de manejo para essa espécie. Com esse intuito, o objetivo do presente trabalho foi avaliar a eficiência de diferentes estratégias de manejo de inverno e de verão sobre o controle de Conyza bonariensis, utilizando a mistura em tanque de glyphosate+2,4-D associada ou não com herbicidas residuais. As combinações de manejo foram realizadas após a colheita do milho safrinha (manejo de inverno), associadas a manejos antecedendo a semeadura da soja (manejo de verão), totalizando 15 tratamentos. Os manejos de inverno avaliados foram eficientes na dessecação das plantas daninhas e mantiveram excelentes niveis de controle residual até a pré-semeadura da cultura da soja. A semeadura da aveia após o manejo de inverno com posterior manejo de verão com glyphosate+2,4D+diclosulam mostrou-se eficiente no controle de Bidens pilosa. Em todos os manejos em que o herbicida 2,4-D foi associado ao glyphosate houve controle total de Conyza bonariensis.
\end{abstract}

Palavras-chave: buva, manejo entressafra, 2,4-D, resistência.

\begin{abstract}
Conyza bonariensis is one of the most important weeds in southern Brazil. The selection of biotypes tolerant and resistant to the herbicide glyphosate has led to increasing demand for alternatives of management strategy to control this species. This work aimed to evaluate the efficiency of different winter and summer management strategy for the control of Conyza bonariensis, by using glyphosate $+2,4-D$ tank mixtures combined or not with residual herbicides. The different burndown alternatives were applied after corn harvest (winter burndown), associated to applications before soybean sowing (summer burndown) with a total of 15 treatments. Winter burndown options evaluated in this research were efficient in weed desiccation and provided excellent levels of residual weed control up to the next summer soybean pre-sowing. The sowing of oats after winter burndown with subsequent summer burndown with glyphosate+diclosulam + 2, 4-D was found to be efficient to control Bidens pilosa. Conyza bonariensis was totally controlled in all the burndown strategies in which the herbicide 2, 4-D was associated to glyphosate.
\end{abstract}

Keywords: horseweed, burndown, 2,4-D, resistance.

\section{INTRODUÇÃO}

Conyza bonariensis e Conyza canadensis são espécies pertencentes à família Asteraceae e têm como centro de dispersão as Américas do Sul e Norte, respectivamente. Conyza bonariensis ocorre intensamente nas zonas subtropicais e temperadas da América do Sul (Kissmann \& Groth, 1999), enquanto Conyza canadensis é uma das espécies mais distribuídas no mundo, sendo encontrada,

1 Recebido para publicação em 29.6.2010 e na forma revisada em 17.12.2010.

2 Engô-Agro ${ }^{-}$., Mestrando do Curso de Pós-Graduação em Agronomia na área de Proteção de Plantas - NAPD/UEM, $<$ am.oliveiraneto@hotmail.com>; ${ }^{3}$ Professor Associado, Núcleo de Estudos Avançados em Ciência das Plantas Daninhas, Universidade Estadual de Maringá - NAPD/UEM, Dep. de Agronomia, Av. Colombo, 5790, 87020-9000 Maringá-PR; ${ }^{4}$ Engoํ-Agr ${ }^{\circ}$., M.Sc., Doutorando do Curso de Pós-Graduação em Agronomia na área de Proteção de Plantas, NAPD/UEM. 
principalmente, nas regiões de clima temperado do hemisfério norte e nas regiões subtropicais do sul (Holm et al., 1997).

A combinação de fatores como a adoção de sistemas que utilizam o baixo revolvimento do solo, como a semeadura direta, e a possibilidade de uso do glyphosate em qualquer estádio fenológico das culturas tolerantes ao glyphosate aumentou a pressão de seleção exercida por esse herbicida e, consequentemente, o risco de aparecimento de plantas daninhas resistentes (Neve et al., 2003).

O primeiro relato de biótipos de Conyza canadensis resistentes ao glyphosate ocorreu nos Estados Unidos (Vangesse1, 2001). Desde então, outros biótipos de buva foram encontrados em diferentes estados norte-americanos e em diversos países (Heap, 2009). No Brasil, foram confirmados casos de resistência de biótipos Conyza bonariensis e C. canadensis ao herbicida glyphosate nos Estados do Rio Grande do Sul (Vargas et al., 2007; Lamego e Vidal, 2008) e São Paulo (Moreira et al., 2007).

A garantia dos rendimentos da cultura da soja e o retardamento da evolução de populações de buva resistentes ao glyphosate através de um manejo antecedendo o estabelecimento da cultura são práticas importantes para redução da pressão dessa planta daninha em ambientes agrícolas (Kruger et al., 2008). Nesse sentido, a associação de herbicidas inibidores da EPSPs com herbicidas de mecanismo de ação alternativo como o 2,4-D, destaca-se como ferramenta eficiente para o controle de buva na operação de dessecação. Segundo Moreira et al. (2007), a associação de glyphosate+2,4-D $\left(1.440+1.005 \mathrm{~g} \mathrm{ha}^{-1}\right)$ foi suficiente para garantir controle eficiente tanto de Conyza bonariensis quanto de Conyza canadensis, em estádios iniciais de desenvolvimento (cinco folhas verdadeiras), 28 dias após a aplicação (DAA). Everitt \& Keeling (2007) relatam que o 2,4-D (1.120 $\left.\mathrm{g} \mathrm{ha}^{-1}\right)$ manteve $83 \%$ de controle de C. canadensis mesmo depois de quatro semanas da aplicação.

Kruger et al. (2008) avaliaram a sensibilidade de quatro populações de $C$. canadensis (duas sensiveis e duas com maior tolerância ao herbicida 2,4-D) e notaram que a dose de 2,4-D necessária para reduzir em 90\% o acúmulo de massa seca em plantas de
C. canadensis ficou no intervalo de 121 a $513 \mathrm{~g} \mathrm{ha}^{-1}$. Para garantir $90 \%$ de controle, a faixa de dose ocupou intervalo de 42 e $107 \mathrm{~g} \mathrm{ha}^{-1}$; esses autores relataram que a diferença entre as doses deve-se à sensibilidade diferencial das populações. O uso associado do herbicida glyphosate com herbicidas inibidores da enzima ALS também se apresenta como uma alternativa a ser utilizada no manejo de biótipos de Conyza sp. resistentes a glyphosate. Trabalhos realizados por Moreira et al. (2007) e Vargas et al. (2007) demonstraram que biótipos resistentes de Conyza bonariensis e Conyza canadensis, em estádios de quatro a cinco folhas, foram eliminados com o uso dos herbicidas chlorimuron-ethyl ou metsulfuron-methyl.

A adoção de técnicas de manejo no período de entressafra (periodo entre a colheita do milho safrinha e a semeadura da soja no verão) que conciliem o controle químico com herbicidas de alto espectro de controle associado a herbicida com atividade residual, combinados com o controle cultural, como a utilização de plantas de cobertura de inverno, é parte fundamental para o manejo de biótipos de C. bonariensis resistentes à glyphosate nos Estados da região Sul.

Com base no exposto, objetivou-se com este trabalho avaliar o desempenho de diferentes estratégias de manejo de inverno e verão após a colheita do milho safrinha, utilizando associações ou não de glyphosate+2,4-D a herbicidas residuais, sobre plantas de Conyza bonariensis e Bidens pilosa.

\section{MATERIAL E MÉTODOS}

Este estudo foi realizado em três manejos de herbicidas após a colheita do milho safrinha. Foi conduzido durante o período de agosto de 2009 a março de 2010 no município de Campo Mourão (S 24ำ'56,14" e W 52º19'21,27", a $571 \mathrm{~m}$ de altitude), em área comercial com histórico de ocorrência de buva resistente ao herbicida glyphosate, a qual havia sido cultivada com milho safrinha após a colheita da soja na safra 2008/2009.

O solo da área experimental apresentava $\mathrm{pH}$ em água de 5,$80 ; 4,28 \mathrm{cmol}_{\mathrm{c}} \mathrm{de}^{+}+\mathrm{Al}^{+3} \mathrm{dm}^{-3}$ de solo; 4,67 $\mathrm{cmol}_{\mathrm{c}} \mathrm{dm}^{-3} \mathrm{de} \mathrm{Ca}^{+2} ; 2,17 \mathrm{cmol}_{\mathrm{c}} \mathrm{dm}^{-3}$ de $\mathrm{Mg}^{+2} ; 0,28 \mathrm{cmol}_{\mathrm{c}} \mathrm{dm}^{-3} \mathrm{de} \mathrm{K}^{+} ; 14,41 \mathrm{mg} \mathrm{dm}^{-3}$ 
de P; 39, $19 \mathrm{~g} \mathrm{dm}^{-3}$ de C; $80 \mathrm{~g} \mathrm{~kg}^{-1}$ de areia grossa; $230 \mathrm{~g} \mathrm{~kg}^{-1} \mathrm{de}$ areia fina; $150 \mathrm{~g} \mathrm{~kg}^{-1}$ de silte; $\mathrm{e}$ $540 \mathrm{~g} \mathrm{~kg}^{-1}$ de argila.

Nos três manejos estudados, as aplicações dos herbicidas foram feitas com pulverizador costal de precisão à base de $\mathrm{CO}_{2}$, em pressão constante de $2,0 \mathrm{~kg} \mathrm{~cm}^{-2}$, equipado com pontas tipo leque XR-110.02, calibrado de forma que proporcionasse volume de calda equivalente a $200 \mathrm{~L} \mathrm{ha}^{-1}$. Os detalhes dos tratamentos utilizados, bem como as doses e épocas de aplicação, estão apresentados na Tabela 1.

As aplicações de manejo de inverno foram realizadas 15 dias após a colheita do milho (27/ 8/2009), com a finalidade de controlar as plantas de $C$. bonariensis em estádios iniciais de desenvolvimento $(15 \mathrm{~cm}$ de altura). Esse cuidado busca atingir as plantas em períodos de menor sensibilidade aos herbicidas de ação total e com menor capacidade de rebrote no início de desenvolvimento vegetativo (Vangessel et al., 2009; Moreira et al., 2010). No momento da aplicação a temperatura média era de $28{ }^{\circ} \mathrm{C}$; a umidade relativa, de $51 \%$; a intensidade dos ventos, inferior a $1 \mathrm{~km} \mathrm{~h}^{-1}$; ausência de nuvens; e o solo encontrava-se parcialmente úmido.

A primeira aplicação do manejo antecedendo o cultivo de verão (16 dias antes da semeadura) foi realizada no dia 9/10/2009, com temperatura, umidade relativa e intensidade dos ventos de, respectivamente, $26{ }^{\circ} \mathrm{C}$, $75 \%$ e $1,5 \mathrm{~km} \mathrm{~h}^{-1}$. A aplicação sequencial (sete dias antes da semeadura) foi realizada no dia $24 / 10 / 2009$, com temperatura média de $28^{\circ} \mathrm{C}$, umidade relativa de $78 \%$ e intensidade dos ventos de 2,1 $\mathrm{km} \mathrm{h}^{-1}$. Em ambas as aplicações o solo estava úmido e o céu parcialmente encoberto por nuvens. A aplicação de glyphosate em pós-emergência da cultura da soja foi feita aos 30 dias pós-semeadura (30 DPS), com temperatura média de $30{ }^{\circ} \mathrm{C}$, umidade relativa de $65 \%$ e intensidade dos ventos de $2,1 \mathrm{~km} \mathrm{~h}^{-1}$; no momento da aplicação o céu estava claro e sem nuvens, e o solo, úmido.

No momento da aplicação do manejo de inverno, C. bonariensis apresentava densidade média de 25 plantas $\mathrm{m}^{-2}$, estádio de desenvolvimento de oito pares de folhas e altura máxima de $15 \mathrm{~cm}$. Outras plantas daninhas, como Richardia brasiliensis (poaia-branca) e

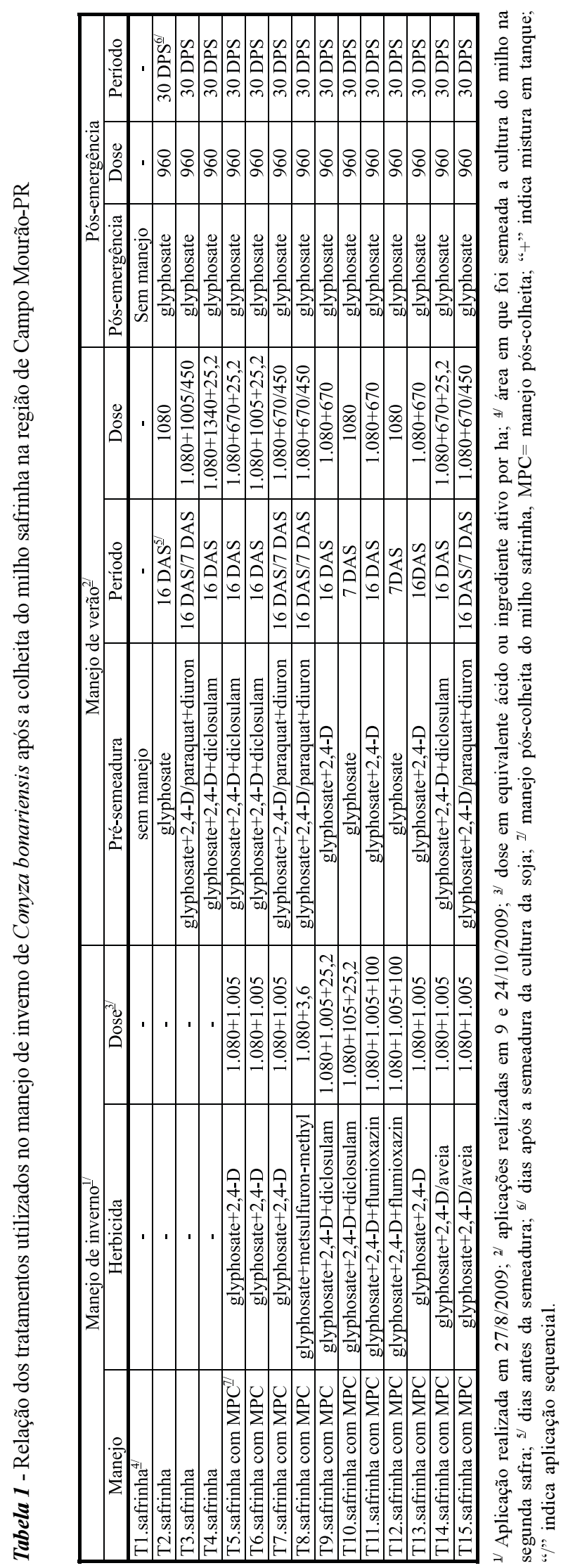


Sonchus oleraceus (serralha), também estavam presentes no momento da aplicação; no entanto, com distribuição e densidade desuniformes, mesmo assim foram consideradas nas avaliações de dessecação e controle geral. Os resíduos culturais do milho safrinha depositados sobre o solo totalizaram $4,36 \mathrm{tha}^{-1}$ e a cobertura do solo, considerando a palha do milho acrescida à biomassa das plantas daninhas no momento da aplicação do manejo de inverno, mostrava-se em 98\%. Os dados de precipitações observados durante o período de condução do experimento constam da Figura 1.

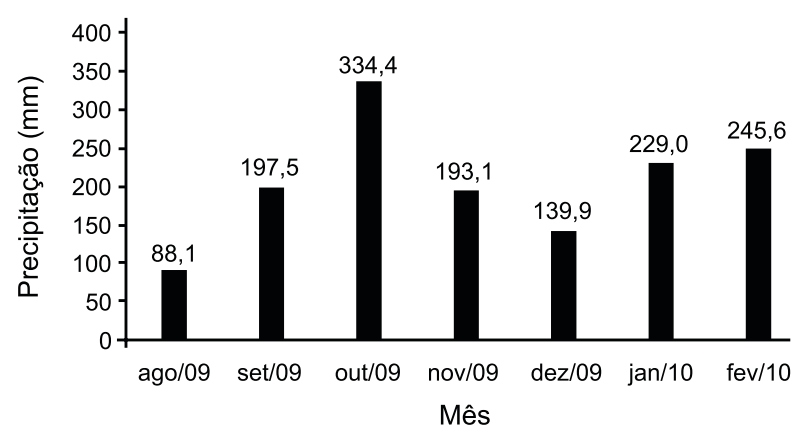

Figura 1 - Precipitação pluvial (mm) no período entre agosto de 2009 e fevereiro de 2010. Dados obtidos na Secretaria de Estado da Agricultura e do Abastecimento, Núcleo Regional de Campo Mourão, Departamento de Economia Rural DERAL.

Três dias após a aplicação dos tratamentos previstos no manejo de inverno, em 30/8/ 2009, realizou-se a semeadura $\left(104 \mathrm{~kg} \mathrm{ha}^{-1}\right)$ a lanço da aveia (Avena sativa) nos tratamentos T14 e T15. Após a distribuição das sementes, houve incorporação delas superficialmente, com o auxílio de um rastelo.

A adubação utilizada na área para a cultura da soja (Glycine max), cultivar CD-214 RR ${ }^{\circledR}$, foi de $250 \mathrm{~kg}$ do formulado $02-20-20$ por hectare. A semeadura direta da cultura ocorreu em $31 / 10 / 2009$, utilizando-se espaçamento entre linhas de $0,45 \mathrm{~m}$ e densidade de 20 sementes por metro linear.

Após a aplicação dos herbicidas, avaliouse a eficiência da dessecação (DES) aos 15 e 30 dias após a aplicação (DAA) por meio da porcentagem de controle, em que $0 \%$ representa ausência de controle e $100 \%$ a morte de todas as plantas da parcela (SBCPD, 1995).
Avaliou-se quinzenalmente a porcentagem geral de controle (CG) até a pré-semeadura da cultura da soja; o padrão de comparação foi a testemunha, que não recebeu manejo (T1). O controle geral refere-se ao efeito pós-emergente (dessecação) e ao efeito préemergente (residual) dos tratamentos. Assim, o CG é o somatório do controle das plantas já emergidas no momento da aplicação, mais o controle das plantas daninhas que emergiram após as aplicações (reinfestação).

A partir dos 30 dias após o manejo de inverno, foi realizada a contagem do número de plantas de buva emergidas por metro quadrado, quinzenalmente, até a pré-semeadura. Essa determinação foi obtida por meio do arremesso (quatro vezes) ao acaso de quadro de $0,25 \mathrm{~m}^{2}$ por parcela. O estádio das plantas de buva foi determinado simultaneamente à contagem. Essas avaliações se estenderam até 30 dias após a semeadura da soja - momento em que foi realizado o tratamento com glyphosate em pós-emergência.

Aos 20 e 30 dias em pós-semeadura (DPS) da cultura da soja, foram realizadas avaliações de porcentagem de controle de picão-preto (Bidens pilosa) que emergiu após a aplicação do manejo de verão. Nessas avaliações, considerou-se o tratamento 13 (glyphosate+2,4-D/ glyphosate+2,4-D) como padrão de comparação, pois não se utilizou herbicida com atividade residual. Também foram realizadas contagens das plantas daninhas por metro quadrado. As plantas de Bidens pilosa presentes na área eram sabidamente resistentes a herbicidas inibidores da ALS.

Depois da aplicação do herbicida glyphosate em pós-emergência aos 30 DPS, foram realizadas duas avaliações visuais de porcentagem de controle de picão-preto (Bidens pilosa) aos 15 e 30 dias após a aplicação do pós-emergente (DAA), seguindo os critérios propostos pela SBCPD (1995).

Por ocasião da colheita da soja avaliou-se a produtividade da cultura, que foi trilhada manualmente e limpa por meio de peneiras; os dados foram corrigidos para $13 \%$ de umidade.

O delineamento utilizado foi o de blocos ao acaso, com 15 tratamentos e quatro repetições, sendo as dimensões da parcela de 
$5,0 \times 4,0\left(20 \mathrm{~m}^{2}\right)$. No entanto, consideraramse como área útil para as avaliações apenas as linhas centrais de cada parcela, exceto 0,50 m de cada extremidade; portanto, a área útil considerada foi de $15,8 \mathrm{~m}^{2}$.

Os resultados foram submetidos à análise de variância pelo teste $\mathrm{F}$ e suas médias comparadas pelo teste de agrupamento de médias de Scott-Knott a 5\% de probabilidade.

\section{RESULTADOS E DISCUSSÃO}

Na Tabela 2 estão expostas as avaliações de porcentagem de dessecação aos 15 e 30 dias após a aplicação do manejo de inverno (DAMI) e porcentagem de controle geral aos 30 DAMI, na pré-dessecação de verão (PREDEV) e na présemeadura da cultura da soja (PRESE). Essas avaliações referem-se à eficiência de cada tratamento sobre as plantas daninhas presentes na área experimental (buva e outras plantas). Nas avaliações de porcentagem de dessecação do manejo de inverno, os tratamentos 2, 3 e 4 não foram avaliados, já que eles não receberam esse manejo.

Aos 15 dias após a aplicação do manejo de inverno os tratamentos 11,12 (gly+2,4$\mathrm{D}+$ flumi), 14 e 15 (glyphosate $+2,4-\mathrm{D} /$ aveia) destacaram-se como os mais efetivos na dessecação, apresentando controles superiores a 94\%. Jaremtchuck et al. (2008) demonstraram que a associação de flumioxazin à mistura de glyphosate e 2,4-D resulta em maior velocidade na dessecação das plantas daninhas, o que realmente ficou evidenciado nos tratamentos 11 e 12 .

Aos 30 DAMI (Tabela 2), todos os tratamentos proporcionaram alta porcentagem de dessecação das plantas daninhas ( $\geq 90,8 \%$ ). Em contrapartida, os tratamentos 6 (glyphosate+2,4-D), 7 (glyphosate+2,4-D), 8 (glyphosate+metsulfuron-methyl) e 13 (glyphosate+2,4-D) mostraram médias inferiores às dos demais, segundo os critérios de agrupamento do teste de Scott-Knott. As menores porcentagens de controle nesses tratamentos deveram-se à presença de plantas de Richardia brasiliensis que não foram totalmente controladas nessa avaliação. C. bonariensis não foi eficientemente controlada pelos tratamentos herbicidas.

Apesar de todos os tratamentos apresentarem de modo geral elevadas porcentagens de controle geral, os tratamentos 9 (glyphosate +2,4-D+diclosulam), 10 (glyphosate+2,4$\mathrm{D}+$ diclosulam), 11 (glyphosate+2,4-D+ flumioxazin), 14 (glyphosate+2,4-D/aveia) e 15 (glyphosate+2,4-D/aveia) destacaram-se, com

Tabela 2 - Porcentagem de dessecação (DES) das plantas daninhas aos 15 e 30 dias após a aplicação do manejo de inverno (DAMI) e porcentagem de controle geral (CG) das plantas daninhas aos 30 DAMI, na pré-dessecação de verão (PREDEV) e présemeadura da cultura da soja (PRESE)

\begin{tabular}{|c|c|c|c|c|c|}
\hline \multirow{2}{*}{ Manejo } & \multicolumn{2}{|c|}{ Dessecação (\%) } & \multicolumn{3}{|c|}{ Controle geral (\%) } \\
\hline & DES 15 DAMI & DES 30 DAMI & CG 30 DAMI & CG PREDEV & CG PRESE \\
\hline $\mathrm{T} 1$ & $0 \mathrm{c}$ & $0 \mathrm{c}$ & $0 \mathrm{c}$ & $0 \mathrm{~d}$ & $0 \mathrm{e}$ \\
\hline $\mathrm{T} 2$ & - & - & - & - & $64,3 \mathrm{~d}$ \\
\hline T3 & - & - & - & - & $87,5 \mathrm{~b}$ \\
\hline $\mathrm{T} 4$ & - & - & - & - & $75,8 \mathrm{c}$ \\
\hline T5 & $87,5 \mathrm{~b}$ & $95,3 \mathrm{a}$ & $94,5 \mathrm{a}$ & $99,5 \mathrm{a}$ & $98,8 \mathrm{a}$ \\
\hline T6 & $84,8 \mathrm{~b}$ & $90,8 \mathrm{~b}$ & $91,0 \mathrm{~b}$ & $99,0 \mathrm{a}$ & $98,0 \mathrm{a}$ \\
\hline T7 & $85,8 \mathrm{~b}$ & $93,0 \mathrm{~b}$ & $93,0 \mathrm{~b}$ & $99,3 \mathrm{a}$ & $99,0 \mathrm{a}$ \\
\hline T8 & $83,8 \mathrm{~b}$ & $91,8 \mathrm{~b}$ & $91,5 \mathrm{~b}$ & $99,0 \mathrm{a}$ & $99,5 \mathrm{a}$ \\
\hline T9 & $81,8 \mathrm{~b}$ & $96,0 \mathrm{a}$ & $97,0 \mathrm{a}$ & $99,0 \mathrm{a}$ & $97,8 \mathrm{a}$ \\
\hline T10 & $89,3 \mathrm{~b}$ & $97,5 \mathrm{a}$ & $97,5 \mathrm{a}$ & $95,8 \mathrm{~b}$ & $97,8 \mathrm{a}$ \\
\hline T11 & $97,3 \mathrm{a}$ & $97,3 \mathrm{a}$ & $97,3 \mathrm{a}$ & $98,8 \mathrm{a}$ & $98,8 \mathrm{a}$ \\
\hline $\mathrm{T} 12$ & $94,0 \mathrm{a}$ & $95,0 \mathrm{a}$ & $95,5 \mathrm{a}$ & $93,3 \mathrm{c}$ & $97,3 \mathrm{a}$ \\
\hline T13 & $83,8 \mathrm{~b}$ & $91,3 \mathrm{~b}$ & $90,8 \mathrm{~b}$ & $98,5 \mathrm{a}$ & $98,3 \mathrm{a}$ \\
\hline T14 & $96,5 \mathrm{a}$ & $97,5 \mathrm{a}$ & $97,5 \mathrm{a}$ & $99,0 \mathrm{a}$ & $99,0 \mathrm{a}$ \\
\hline T15 & $97,0 \mathrm{a}$ & $97,5 \mathrm{a}$ & $97,3 \mathrm{a}$ & $99,8 \mathrm{a}$ & $99,3 \mathrm{a}$ \\
\hline $\mathrm{CV}(\%)$ & 7,40 & 3,54 & 3,29 & 1,82 & 2,37 \\
\hline
\end{tabular}

Médias seguidas de mesma letra minúscula na coluna não diferem entre si pelo teste de Scott-Knott a 5\% de probabilidade. 
controle acima de 97\% (Tabela 2). Observa-se que os tratamentos com melhor porcentagem de controle geral aos 30 DAMI foram os que receberam os herbicidas residuais diclosulam e flumioxazin no manejo de inverno (T9, T10 e T11). Efeitos de controle também foram obtidos nos tratamentos com a presença de aveia (T14 e T15).

$\mathrm{Na}$ avaliação da pré-dessecação com os manejos de verão (PREDEV), a maioria dos tratamentos apresentou controle semelhante, e os únicos tratamentos com controle inferior foram o T10 (glyphosate+2,4-D+diclosulam) e T12 (glyphosate+2,4-D+flumioxazin), com 95,8 e $93,3 \%$, respectivamente (Tabela 2). Sugere-se que essa redução na eficiência dos tratamentos 10 e 12 seja atribuída aos novos fluxos de emergência da sementeira de Bidens pilosa.

Na pré-semeadura da cultura da soja (PRESE), todos os tratamentos que receberam o manejo de inverno e verão tiveram suas médias agrupadas em uma mesma categoria, apresentando elevados niveis de controle (Tabela 2). Contudo, os tratamentos que receberam a aplicação sequencial de paraquat+ diuron (T7, T8 e T15) após o manejo de verão mostraram niveis de controle considerados excelentes $(\geq 99,0 \%)$. O único tratamento que atingiu esse patamar foi o T14 ((glyphosate+ 2,4-D/aveia) / (glyphosate+2,4-D+diclosulam)), que conciliou o uso de aveia no manejo de inverno com o uso de diclosulam no manejo de verão. Os tratamentos que só receberam o manejo de verão (2, 3 e 4) apresentaram niveis de controle geral inferiores aos dos demais em razão de essa avaliação ter sido realizada após 16 dias da aplicação do manejo de verão; dessa forma, não ocorreu o intervalo de tempo mínimo para que os herbicidas proporcionassem eficiente controle.

As avaliações de densidade de plantas de Conyza bonariensis e altura média aos 30 DAMI, na pré-dessecação do manejo de verão (PREDEV) e pré-semeadura da cultura da soja (PRESE), estão apresentadas na Tabela 3. É possivel observar, aos 30 DAMI, que todos os tratamentos com herbicidas reduziram eficientemente a densidade de plantas emergidas de buva, de forma que todos estes tratamentos apresentaram densidades semelhantes.
Na avaliação de pré-dessecação do manejo de verão, apenas os tratamentos 6 (glyphosate+ 2,4-D), 10 (glyphosate+2,4-D+diclosulam) e 12 (glyphosate+2,4-D+flumioxazin) apresentaram pequeno número de indivíduos, porém estes estavam com sintomas avançados de intoxicação. Dessa forma, o manejo de inverno com o herbicida 2,4-D na dose de $1.005 \mathrm{~g} \mathrm{ha}^{-1} \mathrm{em}$ associação com o glyphosate foi eficiente no controle de plantas de buva quando estas se encontravam com altura máxima de $15 \mathrm{~cm}$ no momento da aplicação. Os tratamentos que receberam o manejo de inverno e o de verão não apresentaram mais plantas de buva na avaliação de pré-semeadura (Tabela 3), evidenciando que o uso do manejo antecipado no inverno foi eficiente no controle efetivo dessa planta daninha; os eventuais escapes deste manejo foram eliminados posteriormente, com o manejo de verão.

Atribui-se o sucesso dos manejos adotados em parte à época do ano em que foi realizado o trabalho (final de agosto), pois a partir deste mês a emergência de novas plântulas de buva foi reduzida. Assim, o controle pontual desta é suficiente para minimizar nova infestação. Esse fato pode ser confirmado pelas densidades de plantas no tratamento sem manejo (testemunha), onde a densidade de plantas é similar até a pré-dessecação no manejo de verão e diminui na pré-semeadura da soja, indicando que houve morte das plantas.

Portanto, o somatório dos efeitos do controle pontual eficiente com glyphosate+2,4-D e do estádio adequado da planta daninha no momento da aplicação (máximo $15 \mathrm{~cm}$ ) foi o principal fator que contribuiu significativamente para o bom desempenho dos tratamentos estudados.

Os tratamentos que receberam apenas a dessecação no manejo de verão $(2,3$ e 4$)$ apresentaram plantas de buva até a avaliação de pré-semeadura da cultura; no entanto, as plantas tratadas no manejo de verão tiveram seu crescimento paralisado após a aplicação do manejo de verão (mantiveram altura em torno de $20 \mathrm{~cm}$ ) (Tabela 3). Apenas a testemunha sem manejo e os tratamentos que receberam manejo de verão apresentaram plantas de buva na pré-semeadura da soja, reforçando a eficiência do manejo antecipado de inverno sobre essa planta daninha. A testemunha sem 
Tabela 3 - Densidade e altura média das plantas de Conyza bonariensis (buva) aos 30 dias após a aplicação do manejo de inverno (DAMI), na pré-dessecação de verão (PREDEV) e pré-semeadura da cultura da soja (PRESE)

\begin{tabular}{|c|c|c|c|c|c|c|}
\hline \multirow{2}{*}{ Manejo } & \multicolumn{3}{|c|}{ Densidade (plantas $\mathrm{m}^{-2}$ ) } & \multicolumn{3}{|c|}{ Altura $(\mathrm{cm})$} \\
\hline & 30 DAMI & PREDEV & PRESE & 30 DAMI & PREDEV & PRESE \\
\hline $\mathrm{T} 1$ & $36,75 \mathrm{~d}$ & $35,00 \mathrm{~d}$ & $18,25 \mathrm{~b}$ & 20 & 30 & 45 \\
\hline $\mathrm{T} 2$ & $30,75 \mathrm{c}$ & $30,25 \mathrm{c}$ & $16,25 \mathrm{c}$ & 17 & 20 & 20 \\
\hline T3 & $23,00 \mathrm{~b}$ & $19,25 \mathrm{~b}$ & $13,00 \mathrm{~b}$ & 17 & 20 & 20 \\
\hline $\mathrm{T} 4$ & $21,75 \mathrm{~b}$ & $18,25 \mathrm{~b}$ & $13,00 \mathrm{~b}$ & 17 & 20 & 20 \\
\hline T5 & $0,25 \mathrm{a}$ & $0,00 \mathrm{a}$ & $0,00 \mathrm{a}$ & 10 & - & - \\
\hline T6 & $1,00 \mathrm{a}$ & $0,75 \mathrm{a}$ & $0,00 \mathrm{a}$ & 10 & - & - \\
\hline $\mathrm{T} 7$ & $0,75 \mathrm{a}$ & $0,00 \mathrm{a}$ & $0,00 \mathrm{a}$ & 10 & - & - \\
\hline $\mathrm{T} 8$ & $0,50 \mathrm{a}$ & $0,00 \mathrm{a}$ & $0,00 \mathrm{a}$ & 10 & - & - \\
\hline T9 & $0,00 \mathrm{a}$ & $0,00 \mathrm{a}$ & $0,00 \mathrm{a}$ & - & - & - \\
\hline $\mathrm{T} 10$ & $0,75 \mathrm{a}$ & $1,00 \mathrm{a}$ & $0,00 \mathrm{a}$ & 10 & 10 & - \\
\hline T11 & $0,50 \mathrm{a}$ & $0,00 \mathrm{a}$ & $0,00 \mathrm{a}$ & 10 & - & - \\
\hline $\mathrm{T} 12$ & $0,00 \mathrm{a}$ & $0,75 \mathrm{a}$ & $0,00 \mathrm{a}$ & - & - & - \\
\hline $\mathrm{T} 13$ & $2,50 \mathrm{a}$ & $0,00 \mathrm{a}$ & $0,00 \mathrm{a}$ & 10 & - & - \\
\hline T14 & $0,00 \mathrm{a}$ & $0,00 \mathrm{a}$ & $0,00 \mathrm{a}$ & - & - & - \\
\hline T15 & $0,25 \mathrm{a}$ & $0,00 \mathrm{a}$ & $0,00 \mathrm{a}$ & 10 & - & - \\
\hline $\mathrm{CV}(\%)$ & 22,29 & 23,35 & 31,07 & - & - & - \\
\hline
\end{tabular}

Médias seguidas de mesma letra minúscula na coluna não diferem entre si pelo teste de Scott-Knott a 5\% de probabilidade.

manejo mostrou as maiores alturas médias de plantas de buva, de modo que estas se encontravam com $45 \mathrm{~cm}$ na pré-semeadura da cultura da soja (Tabela 3 ).

As avaliações de porcentagem de controle de picão-preto (Bidens pilosa) realizadas aos 20 e 30 DPS são mostradas na Tabela 4. Os resultados refletiram os beneficios dos diferentes manejos adotados sobre a dinâmica das plantas de Bidens pilosa após a semeadura da cultura da soja. Aos 20 DPS, os sistemas de manejo 3 (glyphosate $+2,4-\mathrm{D} /$ paraquat+ diuron) e 9 (glyphosate+2,4-D+diclosulam/ glyphosate+2,4-D) apresentaram baixas porcentagens de controle, sendo considerados inferiores em relação aos demais. Os tratamentos que conciliaram o manejo de inverno após a colheita do milho safrinha e o uso do herbicida residual diclosulam no manejo de verão (T5 e T6) se destacaram, com as melhores porcentagens de controle residual. Além destes, também se destacaram os manejos em que se realizou a semeadura da aveia após o manejo de inverno (T14 e T15), os quais também mostraram bons niveis de controle $(87,0$ e $87,5 \%$, respectivamente).

Na avaliação de 30 DPS, o manejo de verão com glyphosate+2,4-D seguido da aplicação de paraquat+diuron antes da semeadura da soja
(T3) proporcionou controle semelhante ao do tratamento-padrão (T13); portanto, seu controle foi nulo $(0,0 \%)$. Os manejos T4 e T9 também apresentaram baixas porcentagens de controle: $27,5 \%$ e $17,5 \%$, respectivamente. De forma semelhante, na avaliação de 20 DPS,

Tabela 4 - Porcentagem de controle de Bidens pilosa (picãopreto) aos 20 e 30 dias pós-semeadura da cultura da soja (DPS)

\begin{tabular}{|c|c|c|}
\hline \multirow{2}{*}{ Manejo } & \multicolumn{2}{|c|}{ Controle de picão-preto (\%) } \\
\cline { 2 - 3 } & $20 \mathrm{DPS}$ & $30 \mathrm{DPS}$ \\
\hline $\mathrm{T} 1$ & $0,0 \mathrm{~d}$ & $0,0 \mathrm{~d}$ \\
\hline $\mathrm{T} 2$ & $67,0 \mathrm{~b}$ & $37,5 \mathrm{c}$ \\
\hline $\mathrm{T} 3$ & $28,8 \mathrm{c}$ & $0,0 \mathrm{~d}$ \\
\hline $\mathrm{T} 4$ & $55,0 \mathrm{~b}$ & $27,5 \mathrm{c}$ \\
\hline $\mathrm{T} 5$ & $82,8 \mathrm{a}$ & $72,5 \mathrm{a}$ \\
\hline T6 & $78,3 \mathrm{a}$ & $75,0 \mathrm{a}$ \\
\hline $\mathrm{T} 7$ & $69,0 \mathrm{~b}$ & $45,0 \mathrm{~b}$ \\
\hline T8 & $72,0 \mathrm{~b}$ & $25,0 \mathrm{c}$ \\
\hline T9 & $33,8 \mathrm{c}$ & $17,5 \mathrm{c}$ \\
\hline T10 & $83,8 \mathrm{a}$ & $55,0 \mathrm{~b}$ \\
\hline T11 & $81,3 \mathrm{a}$ & $60,5 \mathrm{~b}$ \\
\hline $\mathrm{T} 12$ & $65,8 \mathrm{~b}$ & $66,3 \mathrm{a}$ \\
\hline T13 & $0,0 \mathrm{~d}$ & $0,0 \mathrm{~d}$ \\
\hline T14 & $87,0 \mathrm{a}$ & $86,3 \mathrm{a}$ \\
\hline T15 & $87,5 \mathrm{a}$ & $78,0 \mathrm{a}$ \\
\hline $\mathrm{CV}(\%)$ & 17,90 & 28,02 \\
\hline
\end{tabular}

Médias seguidas de mesma letra minúscula na coluna não diferem entre si pelo teste de Scott-Knott a $5 \%$ de probabilidade. 
os manejos 5, 6, 14 e 15 foram os que apresentaram os melhores desempenhos. No entanto, onde se realizou o manejo de inverno com glyphosate+2,4-D seguido da semeadura de aveia e no manejo de verão, aos 16 dias antes da semeadura da soja, com glyphosate+2,4$\mathrm{D}+$ diclosulam, a porcentagem de controle de Bidens pilosa foi de $86,3 \%$, ou seja, manteve níveis satisfatórios de controle até 30 dias após a semeadura da soja. Em suma, os tratamentos em que foram realizados o manejo antecipado de inverno e posteriormente o manejo de verão, empregando-se o herbicida diclosulam, mostraram-se eficientes no controle residual de Bidens pilosa.

Os resultados de densidades de plantas de picão-preto e buva nas avaliações de 20 e 30 DPS estão apresentados na Tabela 5. No tratamento que não recebeu manejo (T1), observaram-se baixas densidades de picão-preto em ambas as avaliações, o que se deve à alta densidade de plantas de buva e de poaia-branca, que emergiram e passaram a dominar o ambiente, desfavorecendo a emergência e o desenvolvimento das plantas de picão-preto, por ausência de luz e espaço físico (Souza et al., 2009).

Aos 20 DPS, as menores densidades de picão-preto foram encontradas nos manejos 2 , $5,10,11,14$ e $15: 22,75 ; 15,75 ; 25,00 ; 19,75$; 15,75 ; e 17,00 plantas por $\mathrm{m}^{-2}$, respectivamente. $\mathrm{O}$ único que apresentou densidade de plantas semelhante à do manejo sem residual (T13) foi o manejo 3 (manejo de verão com glyphosate $+2,4-\mathrm{D} /$ paraquat+diuron); os demais tratamentos mostraram densidades inferiores. A adoção deste manejo proporciona excelentes niveis de dessecação, eliminando a maioria das plantas daninhas. Em contrapartida, propicia a incidência da radiação solar sobre o solo, o que pode estimular a reinfestação da área, além de não apresentar atividade residual em pré-emergência.

Na avaliação de 30 DPS, a maioria dos manejos adotados apresentou densidades de picão-preto significativamente inferiores às do manejo sem residual (T13); as únicas exceções foram os manejos T3, T4 e T12, que mostraram densidades de planta semelhantes às observadas no T13. Já os manejos com as menores densidades foram os tratamentos que receberam o manejo de inverno com
Tabela 5 - Densidade de Bidens pilosa (picão-preto) e Conyza bonariensis (buva) aos 20 e 30 dias pós-semeadura da cultura da soja (DPS)

\begin{tabular}{|c|c|c|c|c|}
\hline \multirow{2}{*}{ Manejo } & \multicolumn{2}{|c|}{ Picão-preto (plantas $\mathrm{m}^{-2}$ ) } & \multicolumn{2}{|c|}{ Buva (plantas $\mathrm{m}^{-2}$ ) } \\
\hline & 20 DPS & 30 DPS & 20 DPS & 30 DPS \\
\hline $\mathrm{T} 1$ & $7,00 \mathrm{a}$ & $2,50 \mathrm{a}$ & $21,25 \mathrm{c}$ & $18,50 \mathrm{c}$ \\
\hline $\mathrm{T} 2$ & $22,75 \mathrm{a}$ & $14,75 \mathrm{~b}$ & $11,00 \mathrm{~b}$ & $6,50 \mathrm{~b}$ \\
\hline T3 & $52,75 \mathrm{c}$ & $36,00 \mathrm{~d}$ & $0,00 \mathrm{a}$ & $0,00 \mathrm{a}$ \\
\hline $\mathrm{T} 4$ & $41,00 \mathrm{~b}$ & $29,00 \mathrm{~d}$ & $1,00 \mathrm{a}$ & $0,00 \mathrm{a}$ \\
\hline T5 & $15,75 \mathrm{a}$ & $15,50 \mathrm{~b}$ & $0,00 \mathrm{a}$ & $0,00 \mathrm{a}$ \\
\hline T6 & $35,50 \mathrm{~b}$ & $11,00 \mathrm{a}$ & $0,00 \mathrm{a}$ & $0,00 \mathrm{a}$ \\
\hline $\mathrm{T} 7$ & $34,50 \mathrm{~b}$ & $18,75 \mathrm{~b}$ & $0,00 \mathrm{a}$ & $0,00 \mathrm{a}$ \\
\hline T8 & $37,00 \mathrm{~b}$ & $26,50 \mathrm{c}$ & $0,00 \mathrm{a}$ & $0,00 \mathrm{a}$ \\
\hline T9 & $29,50 \mathrm{~b}$ & $22,50 \mathrm{c}$ & $0,00 \mathrm{a}$ & $0,00 \mathrm{a}$ \\
\hline T10 & $25,00 \mathrm{a}$ & $17,50 \mathrm{~b}$ & $0,00 \mathrm{a}$ & $0,00 \mathrm{a}$ \\
\hline T11 & $19,75 \mathrm{a}$ & $19,50 \mathrm{~b}$ & $0,00 \mathrm{a}$ & $0,00 \mathrm{a}$ \\
\hline T12 & $33,50 \mathrm{~b}$ & $21,75 \mathrm{~d}$ & $0,00 \mathrm{a}$ & $0,00 \mathrm{a}$ \\
\hline T13 & $47,75 \mathrm{c}$ & $32,00 \mathrm{~d}$ & $0,00 \mathrm{a}$ & $0,00 \mathrm{a}$ \\
\hline T14 & $15,75 \mathrm{a}$ & $7,25 \mathrm{a}$ & $0,00 \mathrm{a}$ & $0,00 \mathrm{a}$ \\
\hline T15 & $17,00 \mathrm{a}$ & $13,75 \mathrm{~d}$ & $0,00 \mathrm{a}$ & $0,00 \mathrm{a}$ \\
\hline CV $(\%)$ & 30,74 & 32,13 & 133,20 & 64,41 \\
\hline
\end{tabular}

Médias seguidas de mesma letra minúscula na coluna não diferem entre si pelo teste de Scott-Knott a $5 \%$ de probabilidade.

glyphosate+2,4-D e o herbicida residual diclosulam no manejo de verão e o manejo com semeadura de aveia após o manejo de inverno associado ao manejo de verão com os herbicidas glyphosate+2,4-D+diclosulam (T6 e T14). $\mathrm{O}$ uso da aveia pode ter auxiliado no manejo do picão-preto por meio de liberação de compostos alelopáticos, pois, segundo Jacobi $\&$ Fleck (2000), diferentes cultivares de Avena sp. exsudam quantidades variáveis de escopoletina - composto conhecido como inibidor do crescimento vegetal. Além disso, o sombreamento do solo imposto pela cobertura de aveia pode ter contribuído na inibição da emergência das plantas de buva e picão-preto.

Para a buva, nas avaliações de 20 e 30 DPS, apenas a testemunha que não recebeu nenhum manejo (T1) e o tratamento herbicida glyphosate no manejo de verão (T2) diferiram significativamente dos demais sistemas de manejo, que mantiveram eficiente desempenho sobre a buva (Tabela 5). Esses resultados sugerem que dentro da população de buva da área onde foi conduzido o presente trabalho havia biótipos com maior tolerância ou com resistência ao glyphosate e que o manejo de dessecação com este herbicida não foi suficiente para eliminar essa planta daninha. Entretanto, quando se adicionou o 2,4-D ao glyphosate, a porcentagem de controle foi 
significativamente maior. Resultados positivos também foram verificados nos tratamentos que receberam somente o manejo de verão, onde as plantas apresentavam-se com $20 \mathrm{~cm}$ de altura no momento da aplicação.

Segundo Constantin et al. (2007a), a associação dos herbicidas diclosulam+flumetsulam em pré-emergência reduziu a competição inicial de plantas daninhas com a cultura da soja, cultivar Coodetec 202, e a densidade de emergência de plantas de picão-preto (Bidens pilosa) emergidas no período inicial de desenvolvimento da cultura. A adoção dos manejos de inverno e verão pode ser uma importante estratégia interessante a fim de reduzir a competição inicial de plantas daninhas, sobretudo quando são utilizados herbicidas com atividade residual prolongada na pré-semeadura da cultura da soja.

A aplicação de glyphosate em pós-emergência (30 DPS) foi eficiente no controle de picãopreto a partir dos $15 \mathrm{DAA}$, com porcentagens de controle superior a $90 \%$ não diferindo entre si. Aos 30 DAA, com exceção do manejo 9, que proporcionou $96,8 \%$ de controle, todas as demais formas de manejo proporcionaram controle total de picão-preto. Os resultados de produtividade de grãos de soja são apresentados na Tabela 6. Observa-se que no tratamento testemunha (sem manejo) ocorreu a menor produtividade de grãos $\left(1.289,8 \mathrm{~kg} \mathrm{ha}^{-1}\right)$, de forma que o percentual de redução de rendimento em relação ao manejo 13 (tratamento de maior produtividade) foi de 44,14\%.

Houve redução significativa na produtividade nos manejos $2,6,10,14$ e $15(21,23$; 18,$62 ; 16,09 ; 14,41$; e $16,34 \%$, respectivamente), menor que a do T13. A maior redução de produtividade entre os tratamentos desse grupo foi encontrada no tratamento que não recebeu manejo no inverno e foi dessecado com glyphosate 16 dias antes da semeadura da cultura da soja. Esse fato pode ser atribuído à posição ereta das plantas daninhas, principalmente da buva, no momento da semeadura, o que modifica a qualidade da luz incidente sobre a cultura da soja, provocando o estiolamento da cultura e, posteriormente, a redução na produtividade de grãos (Oliveira Jr. et al., 2006). Esses autores observaram ainda estiolamento da cultura da soja quando emergida antes da morte da cobertura vegetal, devido à
Tabela 6 - Porcentagem de controle de Bidens pilosa (picãopreto) aos 15 e 30 dias após a aplicação (DAA) de glyphosate em pós-emergência e produtividade $\left(\mathrm{kg} \mathrm{ha}^{-1}\right)$ da cultura da soja, após a utilização de diferentes sistemas de manejo de inverno e de pré-semeadura da cultura

\begin{tabular}{|c|c|c|c|}
\hline \multirow{2}{*}{ Manejo } & \multicolumn{2}{|c|}{ Controle picão-preto (\%) } & \multirow{2}{*}{$\begin{array}{c}\text { Produtividade } \\
\left(\mathrm{kg} \mathrm{ha}^{-1}\right)\end{array}$} \\
\hline & $15 \mathrm{DAA}$ & $30 \mathrm{DAA}$ & \\
\hline $\mathrm{T} 1$ & $0,0 \mathrm{~b}$ & $0,0 \mathrm{~b}$ & $1.289,80 \mathrm{c}$ \\
\hline $\mathrm{T} 2$ & $98,3 \mathrm{a}$ & $100,0 \mathrm{a}$ & $1.818,90 \mathrm{~b}$ \\
\hline T3 & $99,5 \mathrm{a}$ & $100,0 \mathrm{a}$ & $2.077,66 \mathrm{a}$ \\
\hline T4 & $99,3 \mathrm{a}$ & $100,0 \mathrm{a}$ & $2.266,36 \mathrm{a}$ \\
\hline T5 & $98,5 \mathrm{a}$ & $100,0 \mathrm{a}$ & $2.194,40 \mathrm{a}$ \\
\hline T6 & $99,3 \mathrm{a}$ & $100,0 \mathrm{a}$ & $1.879,23 \mathrm{~b}$ \\
\hline $\mathrm{T} 7$ & $99,0 \mathrm{a}$ & $100,0 \mathrm{a}$ & $2.102,96 \mathrm{a}$ \\
\hline T8 & $96,8 \mathrm{a}$ & $100,0 \mathrm{a}$ & $2.178,83 \mathrm{a}$ \\
\hline T9 & $90,3 \mathrm{a}$ & $96,8 \mathrm{a}$ & $2.217,70 \mathrm{a}$ \\
\hline $\mathrm{T} 10$ & $99,5 \mathrm{a}$ & $100,0 \mathrm{a}$ & $1.937,60 \mathrm{~b}$ \\
\hline T11 & $100,0 \mathrm{a}$ & $100,0 \mathrm{a}$ & $2.303,33 \mathrm{a}$ \\
\hline $\mathrm{T} 12$ & $97,8 \mathrm{a}$ & $100,0 \mathrm{a}$ & $2.206,06 \mathrm{a}$ \\
\hline $\mathrm{T} 13$ & $97,5 \mathrm{a}$ & $100,0 \mathrm{a}$ & $2.309,16 \mathrm{a}$ \\
\hline T14 & $99,5 \mathrm{a}$ & $100,0 \mathrm{a}$ & $1.976,50 \mathrm{~b}$ \\
\hline T15 & $98,3 \mathrm{a}$ & $100,0 \mathrm{a}$ & $1.931,80 \mathrm{~b}$ \\
\hline CV $(\%)$ & 4,60 & 1,80 & 5,82 \\
\hline
\end{tabular}

Médias seguidas de mesma letra minúscula na coluna não diferem entre si pelo teste de Scott-Knott a $5 \%$ de probabilidade.

busca por uma posição mais elevada no dossel. Esse efeito também foi observado em ensaios conduzidos na cultura do milho por Constantin et al. (2007b, 2008).

As maiores produtividades de grãos foram observadas nos manejos $3,4,5,7,8,9,11,12$ e 13, situadas em mesmo patamar. Os rendimentos de grãos oscilaram entre 2.077,66 e $2.309,16 \mathrm{~kg} \mathrm{ha}^{-1}$ nesses tratamentos.

Nas condições em que foi conduzido este experimento, conclui-se que todos os manejos de inverno foram eficientes na dessecação das plantas daninhas presentes na área. Os tratamentos que receberam os manejos de inverno e verão mantiveram excelentes niveis de controle geral até a pré-semeadura da cultura da soja. Em todos os manejos de inverno e verão nos quais o 2,4-D foi utilizado em associação com glyphosate, houve controle total das plantas emergidas de Conyza bonariensis.

Uma única aplicação de glyphosate em mistura com 2,4-D na dose de $1.005 \mathrm{~g} \mathrm{ha}^{-1}$ foi suficiente para controlar plantas de buva com altura entre 15 e $20 \mathrm{~cm}$. A combinação entre manejo antecipado de inverno e manejo de verão com o herbicida residual diclosulam proporcionou os melhores controles residuais de 
Bidens pilosa após a semeadura da soja. A associação da semeadura da aveia após o manejo de inverno com os herbicidas glyphosate+2,4-D e posteriormente com o manejo de verão com glyphosate+2,4-D+ diclosulam foi o tratamento que apresentou o melhor controle residual de Bidens pilosa. A aplicação de glyphosate em pós-emergência proporcionou niveis excelentes de controle de Bidens pilosa. As maiores reduções de produtividade foram observadas na testemunha sem manejo e no tratamento com glyphosate no manejo de verão e em pós-emergência.

\section{LITERATURA CITADA}

CONSTANTIN, J. et al. Estimativa do período que antecede a interferência de plantas daninhas na cultura da soja, var. coodetec 202, por meio de testemunhas duplas.

Planta Daninha, v. 25, n. 2, p. 231-237, 2007a

CONSTANTIN, J. et al. Interação entre sistemas de manejo e de controle de plantas daninhas em pós-emergência afetando o desenvolvimento e a produtividade do milho.

Planta Daninha, v. 25, n. 3, p. 513-520, 2007 b.

CONSTANTIN, J. et al. Influência do glyphosate na dessecação de capim-braquiária e sobre o desenvolvimento inicial da cultura do milho. Planta Daninha, v. 26, n. 3, p. 627-636, 2008.

EVERITT, J. D.; KEELING, J. W. Weed control and cotton (Gossypium hirsutum) response to preplant applications of dicamba, 2,4-D, and diflufenzopyr plus dicamba.

Weed Technol., v. 21, p. 506-510, 2007

HEAP, I. The international survey of herbicide resistant weeds. Disponível em: http://www.weedscience.com. Acesso em: 10 nov. 2009.

HOLM, E. et al. World weeds. Natural histories and distribuition. Toronto: John Wiley \& Sons, 1997. p. 226-235.

JACOBI, U.S.; FLECK, N.G. Avaliação do potencial alelopático de genótipos de aveia no início do ciclo. Pesq. Agropec. Bras., v. 35, n. 1, p. 11-19, 2000

JAREMTCHUCK, C.C. et al. Efeito de sistemas de manejo sobre a velocidade de dessecação, infestação inicial de plantas daninhas e desenvolvimento e produtividade da cultura da soja. Acta Sci. Agron., v. 30, n. 4, p. 449-455, 2008.
KISSMAN, K. G.; GROTH, D. Plantas infestantes e nocivas. 2.ed. São Paulo: Basf, 1999. v. 2. 978 p.

KRUGER, G. R. et al. Response and survival of rosette-stage horseweed (Conyza canadensis) after exposure to 2,4-D

Weed Sci., v. 56, p. 748-752, 2008

LAMEGO, F. P.; VIDAL, R. A. Resistência ao glyphosate em biótipos de Conyza bonariensis e Conyza canadensis no estado do Rio Grande do Sul, Brasil. Planta Daninha, v. 26, n. 2, p. 467-471, 2008.

MOREIRA, M. S. et al. Resistência de Conyza canadensis e Conyza bonariensis ao herbicida glyphosate.

Planta Daninha, v. 25, n. 1, p. 157-164, 2007.

MOREIRA, M.S. et al. Herbicidas alternativos para o controle de biótipos de Conyza bonariensis e Conyza canadensis resistentes ao glyphosate. Planta Daninha, v. 28 n. 1, p. $167-175,2010$.

NEVE, P. et al. Simulating evolution of glyphosate resistance in Lolium rigidum I: population genetics of a rare resistance trait. Weed Res., v. 43, p. 404-417, 2003.

OLIVEIRA JR., R.S. et al. Interação entre sistemas de manejo e de controle de plantas daninhas em pós-emergência afetando o desenvolvimento e a produtividade da soja

Planta Daninha, v. 24, n. 4, p. 721-732, 2006.

SOCIEDADE BRASILEIRA DA CIÊNCIA DAS PLANTAS DANINHAS (SBCPD). Procedimentos para instalação, avaliação e análise de experimentos com herbicidas. Londrina: $1995.42 \mathrm{p}$

SOUZA, M.C. et al. Emergência de Bidens pilosa em diferentes profundidades de semeadura. Planta Daninha, v. 27, n. 1, p. 29-34, 2009.

VANGESSEL, M. J. Glyphosate resistant horseweed from Delaware. Weed Sci., v. 49, p. 703-705, 2001

VANGESSEL, M. J. et al. Influence of glyphosate-resistant horseweed (Conyza canadensis) growth stage on response to glyphosate applications. Weed Technol., v. 23, n. 1, p. $49-53,2009$

VARGAS, L. et al. Buva (Conyza bonariensis) resistente ao glyphosate na região Sul do Brasil. Planta Daninha, v. 25, n. 3, p. 573-578, 2007. 